\title{
EL QUIJOTE EXPRESIONISTA DE ELIAS CANETTI
}

\author{
Efraín Kristal
}

En este artículo se sostiene que las observaciones de Elias Canetti — premio Nobel de literatura de 1981— sobre Don Quijote, la vida de Cervantes y su arte narrativo ofrecen claves para interpretar su única novela Auto de fe (1935). Las alusiones a la novela de Cervantes en Auto de fe son evidentes en la descripción física de Peter Kien (el sinólogo que pierde su sentido de la realidad después de leer demasiados libros), en su estructura narrativa, y en el procedimiento cervantino que pone en juego las presuposiciones del mundo interior de su protagonista con las de su mundo externo. Si sus diferencias con Cervantes tienen que ver con una estética expresionista (la de Georg Grosz y Franz Kafka) y con el mundo de ideas sociológicas que el propio Canetti elaboró en Masa y poder (1960), sus semejanzas más importantes con el autor de Don Quijote emanan de su preocupación por las relaciones entre los libros y la vida.

Efraín Kristal. Ph. D., Stanford University. Profesor de literatura española y comparada en la Universidad de California en Los Angeles (UCLA). Actualmente es director de la oficina de la Universidad de California en París. En 1998 fue galardonado con el premio Choice (Outstanding Academic Book of the Year Award) por el libro Temptation of the Word: The Novels of Mario Vargas Llosa. Asimismo, es autor de numerosos artículos de crítica literaria en revistas académicas y compilaciones, y de los libros Invisible Work: Borges and Translation (Vanderbilt University Press, 2002), Una visión urbana de los Andes: Génesis y desarrollo del indigenismo en el Perú 1848-1930 (Lima: Instituto de Apoyo Agrario, 1991) y editor de The Cambridge Companion to the Latin American Novel (2005). En 1990 obtuvo el premio Hoopes por la excelencia en la enseñanza de pregrado en la Universidad de Harvard, y el año 2000 el Distinguished Teaching Award de la UCLA.

Estudios Públicos, 100 (primavera 2005). 
$\mathrm{C}$ uando los ancestros de Elias Canetti abandonaron la península ibérica en los días de la expulsión judía su apellido fue "Cañete" como el topónimo del pueblo de donde provino su línea paterna. De paso por Venecia, en camino a Turquía y a Bulgaria donde Canetti nació, el nombre se italianizó. Luego se trasladó a Viena y a otras ciudades germánicas donde el futuro premio Nobel descubrió su vocación literaria, y por fin a Inglaterra el país que lo acogió cuando escapó de la persecución judía de los nazis y donde residió la mayor parte de su vida ${ }^{1}$. Canetti siempre se sintió orgulloso de sus antepasados sefardíes, y supo expresar el cariño especial que tuvo hacia su primer idioma, el de la antigua España: "A veces me siento como un autor español que escribe en alemán. Si leo alguna obra del español antiguo, digamos, La Celestina o Los sueños de Quevedo, tengo la impresión de estar expresándome a través de ella"2.

Canetti llegó tarde a la literatura española, pero leyó el Quijote de niño y a lo largo de los años escribió bellas páginas sobre el padre de la novela moderna. En su celebrada autobiografía manifestó su admiración por Cervantes con palabras que podrían resumir su propio acercamiento a la ficción:

Para mí Don Quijote no es solamente la primera novela, sino que continúa siendo la más grande. En ella no echo de menos nada, ningún conocimiento moderno. Incluso osaría decir lo siguiente: que evita ciertos errores de la psicología moderna. El autor no se propone realizar con ella una investigación del ser humano, no desea mostrar todo lo que acaso se encuentre en el interior de un individuo, sino que crea ciertas unidades que perfila nítidamente y confronta entre sí. De la interacción de esas unidades brota lo que el autor tiene que decir sobre el ser humano ${ }^{3}$.

Canetti fue siempre atento a la suerte de aquellos escritores inconformes con la época que les tocó vivir (“¿Hay algo más aterrador que ir con su tiempo? ¿Hay algo más mortífero?"4); y es así cómo interpreta tanto el destino de Cervantes como su grandeza.

${ }^{1}$ Para una espléndida introducción a la vida y obra de Canetti véase el ensayo introductorio al primer volumen de las obras completas de Canetti por Ignacio Echevarría "Elias Canetti: Perfil de unas Obsesiones", en Masa y poder. Obra completa I, traducción de Juan José del Solar (Barcelona: De Bolsillo, 2005), pp. 11-43.

${ }^{2}$ Michael Hulse (traductor y editor), Essays in Honor of Elias Canetti (New York, Farrar, Straus and Giroux), pp. 111-112. Nota: todas las traducciones, o versiones, de textos citados en lenguas extranjeras son mías.

${ }^{3}$ Elias Canetti, El juego de ojos, en Historia de una vida. Obras completas II (Barcelona: Galaxia Gutenberg, Círculo de lectores, 2003), pp. 815-816.

${ }^{4}$ Elias Canetti, Apuntes 1973-1984 (Barcelona: Galaxia Gutenberg, 2000), p. 97. 
Canetti subraya el trasfondo inquisitorial de España para resaltar el significado de las estratagemas de Cervantes, tanto en su vida como en su obra literaria, para enfrentarse a la realidad histórica de su tiempo:

La calidad moral de Cervantes se manifiesta en su intento exasperado de arreglárselas con las miserables circunstancias de su vida, y con los ajustes que tuvo que hacer para sobrellevar las convenciones oficiales del poder de su tiempo. Por ello se empeña en que la virtud gane en sus obras y se comporta como un buen cristiano. Afortunadamente su esencia, la miseria de su vida concreta, es tan enorme que el conformismo nunca lo pudo sofocar. [Cervantes] superó la sabiduría convencional y la hipocresía de su época ... Su destino atormentado no lo rebajó porque siempre siguió adelante. También amo en él, el hecho de que su fama le llegara tarde, y que a pesar de ello, o quizás por ello, nunca dejó de tener esperanzas. Pese a las muchas falsificaciones de la vida que permitió se introdujeran en sus relatos "idealizados", él amaba la vida tal y como es ${ }^{5}$.

Claudio Guillén ha señalado que la literatura hispánica, probablemente más que cualquier otra, ha estado preocupada con la relación entre la ficción y la vida. Es una literatura que tiende a explayarse entre dos polos. Por un lado están aquellos escritores, como Lope de Vega, que viven para plasmar sus experiencias en las obras que escriben; y por otro aquellos, como Cervantes, que escriben para transformar las vidas de sus lectores. Dentro de estas posibilidades Canetti está claramente del lado de Cervantes. Canetti no desea que se lean novelas como lo hace don Quijote, perdiéndose en el mundo de la ilusión literaria, sino como lo hace un tipo de lector que existe gracias a Cervantes, aquel que lee una obra de ficción con la distancia suficiente para apreciar la ironía de su narrador y la locura de su protagonista. Y la locura de un gran lector es también el tema central de Auto de fe (1935), la única novela que Canetti publicó en su vida ${ }^{6}$.

$\mathrm{Al}$ igual que Cervantes, la investigación de la locura en Canetti no es cínica. Canetti insistió una y otra vez que detrás de la actitud despiadada con la que analizó los desvaríos de la humanidad en sus escritos sociológicos y literarios hay un amor por la vida, y una lucha — que se podría caracterizar de quijotesca - contra la muerte: "He pasado la mayor parte de mi

${ }^{5}$ Elias Canetti, Nachträge aus Hampstead. Aufzeichnungen (Frankfurt: Fischer, 1999), p. 87.

${ }^{6}$ En el origen del proceso de gestación de Auto de fe, Canetti pensaba escribir una "comedia humana" sobre la locura. Estuvo trabajando simultáneamente en las historias de ocho personajes que perdieron la sanidad. En 2024 cuando los archivos de Canetti se hagan públicos, se podrá determinar si todavía existen manuscritos o cuadernos elaborados sobre los otros personajes del proyecto abandonado. 
vida desenmascarando al hombre tal como aparece en las civilizaciones históricas. He analizado y desmenuzado el poder. Hay pocas cosas malas que no tuviera que decir del ser humano y de la humanidad. Y, sin embargo, el orgullo que siento por ellos sigue siendo tan grande que sólo odio verdaderamente una cosa: su enemigo, la muerte"7.

Dado sus propios afanes de escribir sobre la vida "tal y como es", Canetti rechaza las lecturas de Don Quijote que privilegian sus aspectos humorísticos. Para Canetti el humor de la novela, aun en sus momentos más exagerados, es un asunto secundario: "Cuando las ideas son ilusiones, pierden la hueca, gastada falsedad que han acumulado en el curso de una larga tradición literaria. Ésta, claro está, es la grandeza de Don Quijote: la idea y el ideal como una ilusión llevada a sus últimas consecuencias. Que esto sea ridículo o no lo sea no es decisivo: para mí se trata de algo terriblemente serio"8. Lo mismo se podría decir de la novela de Canetti cuyo título en alemán Die Blendung (El deslumbramiento o La ceguera) sugiere una primera orientación para el lector en torno al desvarío de su protagonista, Peter Kien, el sinólogo que prefiere el mundo de sus libros al de la vida real: el deslumbramiento del erudito por los libros corresponde a su ceguera ante la realidad de sus prójimos.

Auto de fe, la traducción española de la novela — que es también su título en inglés y francés-, se refiere a su episodio más memorable, cuando Peter Kien prende fuego a su biblioteca de 25.000 libros inmolándose a sí mismo. Algunos lectores entusiastas de Canetti, entre ellos Salman Rushdie, han alabado el título de la traducción porque evoca "las quemas de libros de la inquisición española" ". En su ensayo sobre Canetti, Rushdie recuerda que fue otro autor alemán, Heinrich Heine, el que dijo “"quien quema libros también quema seres humanos', y de cierto modo ésta es la propuesta que Canetti lleva al extremo para convertirla en algo grotescamente cómico"10.

La quema de los libros en Auto de fe tiene su antecedente literario más ilustre en otro episodio grotescamente cómico: la quema de los libros en Don Quijote. Como si se tratara de una parodia de las sentencias inquisitoriales, el barbero y el cura enjuician a los libros del caballero de la triste figura, como herejes y pecadores a los que se debe castigar o, en algunos II, p. 11.

${ }^{7}$ Elias Canetti, La lengua salvada, en Historia de una vida. Obras completas

${ }^{8}$ Elias Canetti, Nachträge aus Hampstead. Aus den Aufzeichnungen 19541971 (Frankfurt am Main: Fischer, 1999), p. 87.

9 Salman Rushdie, "The Worm of Learning Turns", en Michael Hulse (ed.), Essays in Honor of Elias Canetti (New York: Farrar, Straus and Giroux), p. 84.

${ }^{10}$ Salman Rushdie, "The Worm of Learning Turns", op. cit., p. 85. 
casos, perdonar. Así, por ejemplo, el cura habla de un libro, el cual "como dogmatizador de una secta tan mala, le debemos, sin excusa alguna, condenar al fuego" 11 .

Auto de fe, como la obra maestra de Cervantes, es la historia de un hombre que pierde su sentido de la realidad después de leer demasiados libros. Es también un libro en el cual el realismo y el idealismo se confrontan; los soñadores vulnerables son expuestos a la brutalidad de un mundo violento; y el humor, la comedia, y aún lo grotesco nos invitan a meditar sobre la condición humana. Auto de fe y Don Quijote son novelas que interrogan los peligrosos mecanismos mediante los cuales un espíritu abierto al mundo de las ideas puede perder el contacto con la realidad. Como Tania Hinderberger-Burton lo señaló, en un ensayo pionero sobre el quijotismo en la novela de Canetti, estas "dos novelas tratan las confusiones cómicas y trágicas de un intelecto seducido por los libros"12.

Las alusiones en Auto de fe a la novela de Cervantes y a su protagonista son evidentes desde la descripción física de Kien como un hombre alto, de cara "delgada, severa y huesuda" 13 , pero también son espirituales: "no era incumbencia suya investigar si la supuesta relación entre la exactitud de su memoria y la inequívoca claridad de sus sueños se hallaba legitimada"14.

La Dulcinea de Kien es Teresa, la avara, maliciosa y despiadada ama de casa en quien el erudito proyecta sus idealizaciones de la perfección femenina. En uno de los momentos más citados de la novela, Kien se enamora de la calculadora Teresa cuando la observa palpar un libro de poco valor con guantes blancos. Kien se casa con Teresa, pero, como don Quijote, mantendrá una vida célibe hasta su muerte.

En Auto de fe Georges Kien, el hermano de Peter, asume el papel de Sancho Panza. El psiquiatra, que había sido antes ginecólogo, es un don Juan que dirige un manicomio en París. El célibe Peter es el hombre del intelecto, mientras que Georges es un hombre del cuerpo. Y si Kien es un misógino empedernido, las fuentes de sus diatribas en contra de las mujeres son tan librescas como las de los elogios de Dulcinea por parte de don VI, p. 151.

${ }^{11}$ Cervantes, Don Quijote de la Mancha I (Madrid: Cátedra, 2005), Capítulo

12 Tania Hinderberger-Burton, "The Quixotic in Canetti's Die Blendung", en Modern Austrian Literature, Vol. 16, nos 3/4, 1983, p. 168. La relación entre las dos novelas ha merecido un libro monográfico en el cual Christina Meyer se apoya en los acercamientos de varios teóricos literarios, entre ellos Gérard Genette, para demostrar las relaciones intertextuales entre Cervantes y Canetti. Véase Meyer, Christine, "Comme un autre Don Quichotte". Intertextualités chez Canetti (Paris: ENS Editions), 2001.

${ }^{13}$ Elias Canetti, Auto de fe, prólogo de Ignacio Echevarría, traducción de Juan José del Solar (Barcelona: Debolsillo, 2005), p. 31.

${ }^{14}$ Canetti, Auto de fe, op. cit., p. 36. 
Quijote, como Gemma Gorga lo ha señalado: "La misógina arenga que pronuncia hacia el final del libro en presencia de su hermano Georges es pura erudición, un nutrido catálogo de féminas malvadas extraídas de la mitología y la historia sagrada. Ni Kien ni don Quijote son capaces de ver a la mujer real cuando ésta pasa junto a su lado. Su terror ante lo femenino y su enfermiza soledad les lleva a inventarla — sublimándola en un caso, denigrándola en el otro- para escapar de ella"15.

Una de las relaciones más notables entre Auto de fe y Don Quijote es su estructura narrativa. En la novela de Cervantes don Quijote abandona su casa, que era también su biblioteca, para confrontarse con el mundo exterior sin darse cuenta de que sus percepciones no coinciden con la realidad, y regresa a su casa, no por voluntad propia sino por la intervención astuta de quienes se empeñan en restaurarlo a su estado anterior. En Don Quijote este patrón de salidas y regresos se repite tres veces mientras que en la novela de Canetti se da solamente una vez.

Según el patrón de la salida y el regreso, la primera parte de Auto de $f e$, "Una cabeza sin mundo", cuenta la historia de Peter Kien hasta que Teresa lo expulsa de su casa. La segunda parte, "Un mundo sin cabeza", narra sus encuentros con personajes abusivos como Benedikt Pfaff y Fischerle, los cuales se aprovechan de su credulidad. Y la tercera y última parte, "El mundo en la cabeza", cuenta la historia del regreso de Kien a su casa gracias a la intervención de su hermano.

Un logro supremo de Cervantes es el juego entre las convenciones literarias que determinan el mundo interior de don Quijote y aquellas que confeccionan su mundo exterior ${ }^{16}$. El caballero de la triste figura está convencido de que las novelas de caballería son libros de historia verdadera que hablan de un siglo de oro que él está en condiciones de restaurar, pero no se da cuenta que está viviendo en el mundo brutal de las novelas picarescas. Algo equivalente está en juego en Auto de fe. Kien cree que Pfaff y Fischerle, entre otros personajes sórdidos de un mundo criminal, comparten sus ideales intelectuales porque no los puede ver como son. Si, en sus primeras aventuras, don Quijote se enfrenta a un mundo de bribones, ladrones y prostitutas; Peter Kien se encuentra con un mundo de estafadores, abusadores sexuales y asesinos.

Hay episodios en Auto de fe en los cuales Canetti usa un procedimiento equivalente al de Cervantes cuando yuxtapone la imaginación caba-

\footnotetext{
${ }^{15}$ Gemma Gorga, "El libro ¿tinta o veneno? De Don Quijote a Peter Kien", Cuadernos Hispanoamericanos, 640 (octubre 2003) p. 43.

${ }^{16}$ Stephen Gilman ha resumido este aspecto de la novela de Cervantes con elegancia en La novela según Cervantes (México D.F.: Fondo de Cultura Económica, 1993).
} 
lleresca con la realidad picaresca, como en el capítulo con el título irónico de "La gran piedad", en el cual Canetti describe una casa de empeños como si fuera la corte de un pequeño principado germánico: "Concede audiencia a ciertas horas, recibiendo de preferencia a mendigos o gente dispuesta a serlo. Los visitantes se arrojan a sus pies y, como en los viejos tiempos, le entregan su diezmo. Lo cual no es más que un decir; pues lo que para el corazón principesco es una millonésima parte, para un mendigo es una fortuna" 17 .

Kien es incapaz de sentir mayor simpatía o compasión por cualquier persona de carne y hueso. Los pocos sentimientos nobles que le restan se han desplazado hacia los libros, a los que trata como si fueran seres vivientes, y esa es la mayor expresión de su locura. Cuando Kien cree haber "liberado" algunos libros de las manos del prestamista, hace un discurso que recuerda a una de esas bien intencionadas pero desatinadas arengas de don Quijote: "Seguiremos por el camino que nos hemos trazado. Nuestro óbolo para aliviar la miseria general es muy modesto, pero hay que darlo. Si cada cual se dice a sí mismo: yo, solo, yo demasiado débil, nunca pasará nada y la miseria seguirá haciendo estragos ... ¡A Actuar en vez de berrear! ¡Hechos y no lágrimas!”18

Con la misma inesperada eficacia con la cual Sancho Panza resuelve asuntos prácticos en el gobierno de su "ínsula" en la segunda parte de Don Quijote, Georges rápidamente consigue que su hermano se pueda divorciar de su esposa abusiva; logra quitarle de encima a los embusteros que le habían estado despojando de sus bienes y dinero; consigue reconstituir la biblioteca de su hermano que se había vendido a las casas de empréstitos; y lo restablece en su propia casa.

Canetti ha esbozado una sugerente interpretación sobre la relación entre don Quijote y su escudero según la cual la pareja ofrece una gran riqueza literaria, al subrayar

lo invariable e inquebrantable del carácter tanto de don Quijote como de Sancho Panza; y sin embargo, dentro de estos límites estrictos, su gran riqueza. Qué poco nítidas, qué poco cautivantes, que flojas parecen todas las novelas posteriores cuando se comparan con ésta. Se trata de una retórica del más alto grado, pero dentro de los límites del carácter humano. La retórica caballeresca en contraste con la de los proverbios. El glotón conciliador no está siempre en el error. Los discursos nobles conmueven porque alternan con los discursos de glotonería ${ }^{19}$.

\footnotetext{
${ }^{17}$ Canetti, Auto de fe, op. cit., p. 268.

${ }^{18}$ Canetti, Auto de fe, op. cit., p. 283.

${ }^{19}$ Canetti, Die Fliegenpein. Aufzeichnungen (Frankfurt am Main, 2002), p. 120.
} 
La interpretación de Canetti es brillante, pero limitada para abarcar la pareja cervantina en toda su complejidad. Las ideas de Canetti iluminan ciertos aspectos de los primeros capítulos de Don Quijote con perspicacia, pero el autor del Auto de fe se equivoca con otros puesto que una de las grandezas de la novela de Cervantes consiste precisamente en el proceso mediante el cual don Quijote se transforma en la medida que convive con Sancho Panza y viceversa; y en la creciente complejidad de los dos personajes. Por diferentes que son cuando se conocen, el sentido común de Sancho Panza enriquecerá el mundo interno de don Quijote y el idealismo del caballero despertará la imaginación de su escudero. Habrá momentos en los cuales los papeles iniciales de la pareja se invertirán como en el famoso episodio de la encantada Dulcinea, o en los capítulos que preceden el final de la novela en los que Sancho Panza hace esfuerzos quijotescos para salvar a su compañero de la melancolía que lo consume. Don Quijote es probablemente la más grande obra literaria sobre la amistad, pero éste es un aspecto de la novela al cual Canetti no le ha prestado mayor atención. Como en muchos casos, un error de interpretación por parte de un escritor cuando lee a otro, puede producir un hallazgo literario. Así, la propuesta de Canetti sobre don Quijote y Sancho Panza como representantes de valores invariables es una idea literaria que Canetti supo aprovechar en su propia novela. En Auto de fe sus personajes, de características inalterables, rayan en la caricatura produciendo un efecto literario que sitúa a Canetti en el meollo del mundo germánico en el cual desarrolló sus inquietudes artísticas. Así lo ha señalado Mario Vargas Llosa (autor de un bello libro ilustrado sobre Georg Grosz) cuando compara el acercamiento literario de Canetti a los procedimientos plásticos del expresionismo alemán:

Como en los cuadros de un Kirchner o de Dix, o como los grabados y caricaturas de Grosz, la intensidad y los contrastes de color, la virulencia del trazo, la alteración de la perspectiva, es decir la factura formal de la obra, se adelantan hacia el lector como un espectáculo, revolucionando aquella realidad exterior que el objeto artístico aparenta representar hasta convertirla en una realidad propia, que debe más a la subjetividad y a la destreza del artista que al parecido con el modelo que lo inspiró ... Auto de fe, es como los más logrados de estos cuadros del expresionismo alemán, una pesadilla realista ${ }^{20}$.

Canetti ha llamado a Sancho Panza un "glotón conciliador" y uno podría llamar a Georges un "libertino conciliador". En sus conversaciones

${ }^{20}$ Mario Vargas Llosa, "Una pesadilla realista", en La verdad de las mentiras (Barcelona: Alfaguara, 2002), p. 173. 
con el terco de Peter Georges describe la dinámica de sus "inmutables constancias": "No ves lo que ocurre a tu alrededor, no tienes memoria alguna para tus experiencias personales ... Yo poseo este tipo de memoria que a ti te falta, en eso soy cien veces superior a ti ... Y sólo las dos juntas, memoria afectiva y memoria intelectual (que es la que tú posees) hacen posible al hombre universal. Tal vez te haya sobreestimado. Si ambos pudiéramos fusionarnos en un solo hombre, tú y yo, surgiría un ser espiritualmente perfecto" 21 .

Georges anticipa que su hermano regresará a su estado normal de un intelectual excéntrico, y - en uno de los momentos más extraños de la novela - el narrador revela que tiene la intención de vengarse de su hermano, de humillarle, una vez que recupere su sanidad: "Se reservó una mínima venganza para dentro de unos años. Cuando volviera a visitar a Peter, pues ya había decidido esa visita, le expondría en forma amable, aunque despiadada, lo que de verdad había ocurrido entre los dos"22. Este toque perverso matiza la impresión que el lector podría tener de Georges, porque hay un elemento de malicia, aun en el personaje que ha demostrado la mayor benevolencia hacia Kien en la novela. Y si hay malicia en Georges, el final de la novela representa a Kien como un personaje decididamente diabólico.

La imagen final del libro, la de Kien como una figura endemoniada y destructora riéndose a carcajadas "como jamás se había reído en toda su vida" ${ }^{23}$ mientras que las llamas consumen sus más preciadas posesiones, es la menos cervantina de la novela, porque en sus delirios más excéntricos las intenciones de don Quijote son bondadosas, pero ese desvío de su ilustre antecedente, es también su vínculo más directo con las ideas sociológicas del propio Canetti. Como Olivier Agard lo ha señalado, el protagonista de Auto de fe es el antecedente a las reflexiones sociológicas de Canetti sobre el poder y la tiranía: "Kien presenta todos las características del tirano paranoico tal como Canetti lo describirá más tarde en Masa y poder"24.

Para Canetti el fenómeno fundamental de la experiencia humana es la tensión inevitable entre el individuo y la masa. Canetti ha resumido su intuición central al afirmar que existe "un instinto de masa en permanente conflicto con el instinto individualista, y que la lucha entre ambos permitía explicar el curso de la historia humana"25.

${ }^{21}$ Canetti, Auto de fe, op. cit., p. 558.

22 Ibídem, p. 561.

${ }^{23}$ Ibídem, p. 591.

${ }^{24}$ Olivier Agard, Elias Canetti. L'explorateur de la mémoire (Paris: Belin, 2003), p. 70.

25 Canetti, La antorcha al oído, en Historia de una vida. Obras completas II (Barcelona: Galaxia Gutenberg, Círculo de lectores, 2003), p. 509. 
La masa para Canetti es un fenómeno ambiguo: es el medio por excelencia mediante el cual el individuo "supera los límites de su propia persona" 26 , pero la masa es también la expresión por excelencia "del impulso de destrucción"27. Canetti insiste que el fuego incendiario - por su fuerza destructora - es "el más intenso y antiguo símbolo de masa" 28 , y como tal "ha pasado a integrarse en la configuración psíquica del hombre y constituye una parte inalterable de ella"29.

En sus escritos autobiográficos, Canetti indicó que para entender la masa tenía que entender "el instinto de masa" en el individuo más aislado: "Jamás entendería a la masa sin antes saber qué era el aislamiento extremo"30. En Masa y poder Canetti discute esos "actos incendiarios impulsivos ... para el individuo que los comete, aquel individuo que está realmente aislado y no pertenece al ámbito de ningún credo religioso o político"31.

Cualquiera que sea el alcance antropológico de las ideas de Canetti sobre la masa y el fuego, sus propuestas en Masa y poder aclaran las ideas que inspiraron la inmolación de Kien en su novela: la locura de Kien es una parodia grotesca del tirano. En Auto de fe, por lo tanto, Peter Kien no es una simple víctima inocente de sus circunstancias, sino un hombre peligroso. Por eso la muerte de Kien es, desde el punto de vista del propio Canetti, un castigo que él, como autor de su libro, le impone al personaje que se apropia indebidamente del derecho de enjuiciar: "el castigo más grave, sin embargo, se imponía al que se arrogaba el derecho de condenar a los demás"32.

El propio Canetti interpretó el significado de su novela como un diagnóstico del momento que le tocó vivir: "Nunca sentí tan intensamente como en aquel momento, tras la catástrofe de Kien, los peligros que amenazaban al mundo en que nos encontramos ... Todo lo que yo veía ahora, me encontrase donde me encontrase, se hallaba al borde de una catástrofe que podía sobrevenir de un momento a otro" 33 . Canetti le otorga una dimensión profética a su ficción: "todo parece haber surgido en las noches de bombardeos de la guerra mundial que aún estaba por llegar"34.

Dado el hecho de que Canetti ha expresado una pasión por los libros que se aproxima a la del protagonista de su novela, la destrucción de Kien

\footnotetext{
${ }^{26}$ Canetti, Masa y poder, op. cit., p. 76.

${ }^{27}$ Ibídem, p. 75.

${ }^{28}$ Ibídem, p. 84.

${ }^{29}$ Ibídem, p. 86.

${ }^{30}$ Canetti, La antorcha al oído, op. cit., p. 647.

${ }^{31}$ Canetti, Masa y poder, op. cit., p. 155.

32 Canetti, El juego de ojos, op. cit., p. 780.

33 Ibídem, p. 778.

34 Ibídem, p. 779.
} 
es también un gesto simbólico, si no de autocrítica, por lo menos de ironía hacia su propio ser. Canetti ha dicho "me duele no ocuparme de los libros, tengo un sentimiento físico por ellos, de vez en cuando me sorprendo en diálogos de despedida con ellos"35. Esta actitud lo vincula nuevamente a sus ideas sobre Cervantes.

En La agonía de las moscas, Canetti escribe que en la "retórica de la experiencia" de Cervantes, Don Quijote es un vehículo mediante el cual el autor se burla de sí mismo ${ }^{36}$. Se podría decir que en Auto de fe Canetti se burla seriamente de sí mismo. Peter Kien, el protagonista de la novela, como Canetti, es un amante de los libros y un amante de la literatura y del pensamiento de la $\mathrm{China}^{37}$.

Para Canetti, entonces, el intenso interés de Peter Kien por la literatura china no es ni trivial ni excéntrico. Es un interés que el propio Canetti compartió con su personaje: "a pesar de no conocer el idioma, amo todo lo que sea chino" 38 . Es notable, además, que uno de los mayores cumplidos que Canetti le ha brindado a Franz Kafka — su autor preferido del siglo XX - es llamarlo "el único escritor esencialmente chino que se puede encontrar en el occidente" 39 .

El sinólogo enloquecido de Canetti tiene dimensiones diabólicas que no se encuentran en Cervantes, pero que sí están presentes en el Quijote de Kafka, tal como lo imaginó en su brevísimo relato "La verdad sobre Sancho Panza”. El Quijote de Kafka es un demonio peligroso al cual Sancho Panza le proporciona novelas de caballería y sobre bandoleros hasta que enloquece. El propósito de Sancho es el de protegerse a sí mismo y a los demás de este personaje diabólico. Sancho Panza acompaña a don Quijote en sus "más locas aventuras" primero por un sentimiento de responsabilidad, y luego por su entretenimiento ${ }^{40}$. Georges, como el Sancho de Kafka, se entretiene con la locura de su hermano, y hasta aquí llegan las semejanzas entre la novela de Canetti y el relato, porque, a diferencia de Kafka, Canetti castiga a su lector empedernido.

La falla de Kien no es que ame los libros ni que se haya interesado por temas que algunos podrían considerar como esotéricos, sino que cree que puede divorciar su mundo interno de las preocupaciones humanas de

\footnotetext{
${ }^{35}$ Canetti, Apuntes 1973-1984, op. cit., p. 46.

${ }^{36}$ Elias Canetti, Die Fliegenpein, op. cit., p. 119.

${ }^{37}$ Elias Canetti, The Human Province (New York: The Seabury Press, 1978),

${ }^{38}$ Canetti, Nachträge aus Hampstead, op. cit., p. 186.

${ }^{39}$ Elias Canetti, The Conscience of Words (New York: The Seabury Press,

${ }^{40}$ Franz Kafka, Erzählungen (Frankfurt am Main: Fischer, 2003), p. 350.
} pp. 256. 1979), p. 121. 
sus prójimos. La actitud de Kien no podría estar más alejada del espíritu de los aspectos de la cultura china que Canetti admiró y sintió como propios. En una de sus muchas reflexiones sobre la sabiduría china, Canetti dice: "Se trata siempre de las actitudes en torno a la vida y no sobre los conceptos" 41 .

Canetti escribe que "una persona que piensa que puede separar su mundo interno de su mundo externo carece de un verdadero mundo interno" ${ }^{2}$. En otras palabras, un genuino mundo interno está más allá de las posibilidades de quienes están demasiado absortos con sí mismos, y de los que no están en condiciones de reconocer el derecho del prójimo a nuestra atención. Para John Bayley ésta es la frase más importante que Canetti haya escrito, y sin duda es una idea que está detrás de la invención de Kien, el personaje en el cual Canetti proyectó el mayor temor que tenía sobre los riesgos de su propia condición intelectual: un amante de los libros que se ha enajenado de la humanidad.

En uno de los momentos más irónicos de la novela, Peter Kien hace una observación que lo podría haber salvado de la locura y del suicidio, si la hubiese tomado realmente en serio: "Avanzamos a ciegas por la vida. ¿Qué vemos de toda la atroz miseria que nos rodea?"43 Pero Kien ha estado demasiado alejado de la realidad humana como para apreciar la miseria de sus prójimos, y por eso Canetti lo ejecuta brutalmente en las últimas páginas de la novela como si deseara exorcizar sus propias inclinaciones para ignorar el mundo exterior, el mundo humano.

Las raíces cervantinas más profundas de la novela de Canetti están en su preocupación por las relaciones entre la literatura y la vida para que la imaginación literaria que atesora no se divorcie de la experiencia humana. En una de sus más bellas reflexiones sobre los pesares de Cervantes, Canetti resumió su propio ideal como escritor: "Gracias a la escritura no sucumbió, pero tampoco se excedió: la riqueza de sus vivencias nunca fueron abrumadas por la fuerza de su escritura" 44 .

${ }^{41}$ Elias Canetti, Die Provinz des Menschen. Aufzeichnungen 1942-1972 (Frankfurt: Fischer, 2003), p. 334.

${ }^{42}$ Citado por John Bayley en Michael Hulse (tr.) Essays in Honor of Elias Canetti, p. 132.

${ }^{43}$ Canetti, Auto de fe, op. cit., p. 278.

${ }^{44}$ Elias Canetti, Die Fliegenpein (Frankfurt: Fischer, 2002), p. 113. 